\title{
Good prescribing: better systems and prescribers needed
}

\author{
Simon Maxwell MD PhD
}

Previously published at www.cmaj.ca

$\infty$ See related research articles by Shojania and colleagues and by Villeneuve and colleagues, published Mar. 23

$\mathrm{P}$ rescribing is at the core of the therapeutic efforts made by doctors both in hospital and in primary care. Observational studies have highlighted the challenges to delivering high-quality clinical outcomes for patients in both settings. Avoidable adverse effects of medicines are a common cause of admission to hospital ${ }^{1}$ and occur frequently in those who are admitted. ${ }^{2}$ Medication errors are also common. A recent prospective observational study in the United Kingdom showed that $10 \%$ of prescriptions in hospital contained errors and that senior doctors were culpable almost as frequently as recent graduates. ${ }^{3}$ Patients are often denied some of the most evidence-based treatments while being maintained on those that are unnecessary. ${ }^{4,5}$ Finally, rates of adherence to long-term therapy are often low, ${ }^{6}$ which calls into question the confidence that patients have in their physicians and the medicines they prescribe.

For prescribing to be of high quality, it should be safe, effective, cost-effective and patient-centred. ${ }^{7}$ Perhaps we should not be surprised that it often falls short of this ideal. Prescribing is a complex task that requires diagnostic skills, knowledge of medicines, communication skills, an understanding of the principles of clinical pharmacology, appreciation of risk and uncertainty and, ideally, experience. The demands placed on prescribers are also rising because of the increased choice of medicines available, expanding indications for drug treatment, greater complexity of treatment regimens and associated polypharmacy, and a growing elderly patient population. The other major challenge is the pace of change in therapeutics. New evidence on effectiveness, emerging safety signals and changing costs means that what is considered good prescribing today may not necessarily be so in a year.

The sheer volume of prescriptions means that some poor outcomes are inevitable. However, every effort should be made to improve quality and minimize risk. Two research articles published recently in $C M A J$ illustrate the difficulties in achieving such improvements. In the first, Shojania and colleagues report their findings from a systematic review of randomized studies evaluating improvements in processes of care from computer reminders delivered to clinicians during routine electronic ordering or charting activities. ${ }^{8}$ Across the 28 trials (reporting 32 comparisons), the authors found that computer reminders improved adherence to processes of care (appropriate prescribing or ordering of tests) by a median of only $4.2 \%$. Systems that required users to enter a response provided larger improvements (median 12.9\%). The largest

\section{Key points}

- Prescribing often falls short of the ideal of being safe, effective, cost-effective and patient-centred.

- Improving prescribing practices and clinical outcomes is an important challenge for all health care providers.

- Interventions targeted at individual prescribers and the systems in which they work can help to improve prescribing.

- Important approaches include undergraduate and postgraduate education, local formularies, incentive schemes, review and feedback on prescribing, and computerized physician order entry with decision support.

effect (median 16.8\%) was seen in one institution with a welldeveloped, "homegrown" clinical information system. Although there is little information about the baseline performance or clinical outcomes, these modest gains should make us reconsider the extent of our expectations for computer reminder systems.

In the second article, Villeneuve and colleagues report on their investigation into the efficacy of a collaborative model involving family physicians and community pharmacists in improving the care of patients with dyslipidemia. ${ }^{9}$ The pharmacists counselled patients about their medications and lifestyle changes, requested laboratory tests, monitored the effectiveness and safety of medications and patients' adherence to treatment, and adjusted medication dosages. Compared with patients assigned to receive usual care (presumably reflecting a more cautious or cost-effective approach of the pharmacists), patients in the collaborative care group were much less likely to receive high-potency statins, had more visits with health care professionals and more laboratory tests, and were more likely to have their lipid-lowering treatment changed and to report lifestyle changes. After a year of follow-up, the mean reduction in low-density lipoprotein (LDL) cholesterol in the collaborative care group was small and only slightly better than the reduction in the usual care group (crude difference $-0.2 \mathrm{mmol} / \mathrm{L}$; adjusted difference $-0.05 \mathrm{mmol} / \mathrm{L})$.

From the Clinical Pharmacology Unit, University of Edinburgh, Clinical Research Centre, Western General Hospital, Edinburgh, UK

CMAJ 2010. DOI:10.1503/cmaj.100335

All editorial matter in CMAJ represents the opinions of the authors and not necessarily those of the Canadian Medical Association. 
Taken together, these articles imply that achieving meaningful improvements in prescribing behaviour is difficult. However, any pessimism should be mitigated by the apparent success of the pharmaceutical industry. With a careful and well-funded combination of attractive literature, development of personal relationships, product placement, and educational events often involving subtle support for new products by key opinion leaders, the pharmaceutical industry very effectively manages to change prescribing habits. As Moynihan put it, "Food, flattery and friendship are all powerful tools of persuasion, particularly when combined." 10 But the industry is also methodical in its approach: drug representatives get to know their physicians, analyze what they do and use this as the basis for seeking change. ${ }^{11}$

Could publicly funded health care systems be as effective as the pharmaceutical industry? Although they cannot flex the same financial muscle, they do have power, as employers and regulators, to exert their own influence on individual prescribers and the environments in which they work.

Prescribers could be better equipped to confront the pressures they face. First, and foremost, all doctors need to start their careers with a firm understanding of clinical pharmacology, the science that underpins rational use of medicines. This will enable them to critically evaluate the many sources of information they get and respond to change. Medical schools should respond to the widespread concerns about adverse medication events by making competence in prescribing a prominent feature of their curricula and assessments. This education process should continue into the postgraduate years, with protected time to attend professional development programs led by the service rather than by the pharmaceutical industry. Prescribers are influenced by meaningful feedback on quality markers, such as antibiotic use, ${ }^{12}$ and should be given information that allows them to reflect on and change their current prescribing practices. Clinical units should audit adverse medication events at regular intervals.

Health care systems could do more to improve matters. The development of formularies can change prescribing practice, especially if they are locally owned and supported. ${ }^{13}$ Incentive schemes are also an effective means of promoting the use of evidence-based and cost-effective prescribing. ${ }^{14}$ The checking and review of prescriptions by prescribing colleagues and other professionals such as nurses and pharmacists could be embedded into routine practice. Pharmacists not only prevent errors reaching patients $\mathrm{s}^{3}$ but can also support the prescribing process by educating patients and improving clinical outcomes. ${ }^{915}$ Notwithstanding the reservations that arise from the study by Shojania and colleagues, ${ }^{8}$ computer reminder systems, and their associated decision support tools, will play an increasingly important role in minimizing error and helping physicians to make good prescribing choices. However, despite their increasing sophistication, these reminder systems do not prescribe, they simply provide further information on which decisions can be based. Prescribers will still be called upon to make judgments about warnings and other information alerts that will, ultimately, be influenced by their individual training and instincts.

Competing interests: None declared.

\section{REFERENCES}

1. Leendertse AJ, Egberts ACG, Stoker LJ, et al.; HARM Study Group. Frequency of and risk factors for preventable medication-related hospital admissions in the Netherlands. Arch Intern Med 2008;168:1890-6.

2. Davies EC, Green CF, Taylor S, et al. Adverse drug reactions in hospital in patients: a prospective analysis of 3695 patient-episodes. PLoS One 2009;4:e4439. doi:10.1371/journal.pone.0004439.

3. Dornan T, Ashcroft D, Heathfield $\mathrm{H}$, et al. An in depth investigation into causes of prescribing errors by foundation trainees in relation to their medical education - EQUIP study. London (UK): General Medical Council; 2009. Available: www.gmc-uk.org/FINAL_Report_prevalence_and_causes_of_prescribing_errors .pdf_28935150.pdf (accessed 2010 Mar. 4).

4. Kanji S, Corman C, Douen AG. Blood pressure management in acute stroke: comparison of current guidelines with prescribing patterns. Can J Neurol Sci 2002;29: 125-31.

5. Aronson JK. Prescribing statins. Br J Clin Pharmacol 2005;60:457-8.

6. Caro JJ, Speckman JL, Salas M, et al. Effect of initial drug choice on persistence with antihypertensive therapy: the importance of actual practice data. CMAJ 1999; 160:41-6.

7. British Pharmacological Society. Ten principles of good prescribing. London (UK) The Society; 2010. Available: www.bps.ac.uk/guidelines/BPSPrescribingPrinciples .pdf (accessed 2010 Mar. 4).

8. Shojania KG, Jennings A, Mayhew A, et al. Effect of point-of-care compute reminders on physician behaviour: a systematic review. CMAJ 2010;182:458-64.

9. Villeneuve J, Genest J, Blais L, et al. A cluster randomized controlled Trial to Evaluate an Ambulatory primary care Management program for patients with dyslipidemia: the TEAM study. CMAJ 2010;182:447-55.

10. Moynihan R. Who pays for the pizza? Redefining the relationships between doctors and drug companies. 1: Entanglement. BMJ 2003;326:1189-92.

11. Fugh-Berman A, Ahari S. Following the script: how drug reps make friends and influence doctors. PLoS Medicine 2007;4:621-5.

12. Zwar $\mathrm{N}$, Henderson $\mathrm{J}$, Britt $\mathrm{H}$, et al. Influencing antibiotic prescribing by prescriber feedback and management guidelines: a 5-year follow-up. Fam Pract 2002; 19:12-7.

13. Gunnarsdóttir AI, Kinnear M. Factors that influence prescribers in their selection and use of COX-2 selective inhibitors as opposed to non-selective NSAIDs. Pharm World Sci 2005;27:316-20.

14. Bateman DN, Campbell M, Donaldson L, et al. A prescribing incentive scheme for non-fundholding general practices: an observational study. BMJ 1996;313:535-8.

15. Carter BL, Ardery G, Dawson JD, et al. Physician and pharmacist collaboration to improve blood pressure control. Arch Intern Med 2009;169:1996-2002.

Correspondence to: Prof. Simon Maxwell, Clinical Pharmacology Unit, University of Edinburgh, Clinical Research Centre, Western General Hospital, Edinburgh EH4 2XU, UK; s.maxwell@ed.ac.uk 